\title{
Cukrzyca u chorego na przewlekłą białaczkę szpikową skutecznie leczonego nilotynibem
}

\author{
Diabetes mellitus in a patient with chronic myelogenous leukemia \\ successfully treated with nilotinib
}

\author{
Joanna Niesiobędzka-Krężel \\ Katedra i Klinika Hematologii, Onkologii i Chorób Wewnętrznych, Warszawski Uniwersytet Medyczny
}

\begin{abstract}
Streszczenie
Leczenie inhibitorami kinaz tyrozynowych jest standardem postepowania w przewlektej biataczce szpikowej. W przypadku nieskuteczności imatynibu w pierwszej linii znaczna czéść chorych odnosi korzyść z leczenia nilotynibem lub dazatynibem $w$ drugiej linii, uzyskujac catkowita remisje cytogenetyczna i większa molekularna. Terapia może być jednak powiktana dziataniami niepożadanymi, do których w przypadku nilotynibu należy cukrzyca. Monitorowanie wyników badań laboratoryjnych, modyfikacja stylu życia i wtaczenie w odpowiednim momencie leczenia przeciwcukrzycowego zapewniaja możliwość dalszego skutecznego leczenia biataczki. Opisany przypadek dotyczy chorej skutecznie leczonej nitotynibem, po niepowodzeniu terapii imatynibem, u której wystapiła cukrzyca. Zastosowanie doustnych leków przeciwcukrzycowych spowodowato poprawe $i$ umożliwito kontynuacje leczenia nilotynibem.
\end{abstract}

Słowa kluczowe: przewlekła białaczka szpikowa, inhibitory kinaz tyrozynowych, imatynib, nilotynib, cukrzyca

Hematologia 2017; 8, supl. B: B15-B20

\begin{abstract}
Treatment with tyrosine kinase inhibitors is a standard procedure in chronic myelogenous leukemia. In case of ineffective treatment with imatinib in first line therapy a lot of patients benefit from treatment with nilotinib or dasatinib in the second line obtaining complete cytogenetic response and major molecular response. However the treatment can be complicated by side effects such as diabetes mellitus in case of nilotinib treatment. Monitoring laboratory tests results, lifestyle modification and beginning antidiabetic therapy at the proper time enable further successful treatment with nilotinib. The case presented concerns the patient whose successful treatment with nilotinib, after the failure with imatinib treatment, was complicated by diabetes mellitus. Oral antidiabetic drugs application improved the situation and enabled to continue nilotinib treatment.
\end{abstract}

Key words: chronic myelogenous leukemia, tyrosine kinase inhibitors, imatinib, nilotinib, diabetes mellitus

Hematologia 2017; 8, supl. B: B15-B20

Adres do korespondencji: Joanna Niesiobędzka-Krężel, Katedra i Klinika Hematologii, Onkologii i Chorób Wewnętrznych, Warszawski Uniwersytet Medyczny, ul. Banacha 1A, 02-097 Warszawa, tel. 2259928 98, faks 22 559 14 18, e-mail:krezel@mp.pl 


\section{Wprowadzenie}

Przewlekła białaczka szpikowa (CML, chronic myelogenous leukemia) należy do nowotworów mieloproliferacyjnych. Jej istotą jest klonalny rozrost zmienionej nowotworowo wielopotencjalnej komórki macierzystej szpiku. Jest to choroba nabyta o nieznanej etiologii. Rzadko występuje częstość zachorowań wynosi 1-2/100 tys. osób/ /rok i stwierdza się ją nieco częściej u mężczyzn niż u kobiet (1,3:1). Jest chorobą osób dojrzałych i starszych: średnia wieku w momencie rozpoznania to około 60 lat, ale coraz częściej diagnozuje się ją u młodych pacjentów [1].

Przewlekła białaczka szpikowa jest pierwszą nowotworową chorobą rozpoznaną na poziomach genetycznym i molekularnym. Istotą zburzeń jest translokacja materiału genetycznego $\mathrm{w}$ postaci części długich ramion między chromosomami 9. i $22 . \mathrm{t}(9 ; 22)(\mathrm{q} 34 ; \mathrm{q} 11)$. Zamiana ta prowadzi do przemieszczenia protonkogenu $A B L 1 \mathrm{z}$ chromosomu 9. na chromosom 22. Powstaje w ten sposób chromosom Filadelfia (Ph, Philadelphia) z genem fuzyjnym $B C R-A B L 1$ kodującym białko o aktywności kinazy tyrozynowej. Po raz pierwszy opisali to w 1960 roku Nowell i Hungerford [2], a potwierdziła w 1973 roku Janet Rowley [3], która wykazała, że powstanie patologicznego chromosomu jest wynikiem tej translokacji.

Kodowane przez onkogen $B C R-A B L 1$ białko (najczęściej p210, rzadziej p190 lub p230) znajduje się w cytoplazmie i ma wzmożoną aktywność kinazy tyrozynowej. Powoduje aktywację szlaków przekazywania sygnałów i w efekcie prowadzi do proliferacji klonu białaczkowego komórek macierzystych szpiku, zahamowania ich apoptozy, upośledzenia przylegania do podścieliska przez zaburzenie funkcji integryn. Liczba komórek białaczkowych zwiększa się zarówno w szpiku, jak i w krwi obwodowej [4].

Przełomem w leczeniu CML było pojawienie się inhibitorów kinaz tyrozynowych (TKI, tyrosine kinase inhibitor). Pierwszym lekiem $\mathrm{z}$ tej grupy był imatynib (IM). W badaniu IRIS (International Randomised Study of Interferon and STI571) udowodniono jego skuteczność i stało się ono podstawą do rejestracji leku w 2001 roku przez amerykańską Agencję ds. Żywności i Leków (FDI, Food and Drug Administration). Od tego czasu IM stał się podstawą terapii CML [5]. Kilka lat później opracowano TKI II generacji. Pierwszym lekiem $z$ tej grupy był dazatynib (DAZA), który zarejestrowano do leczenia CML w drugiej linii w 2006 roku, a następnie w pierwszej linii w 2010 roku, i nilotynib (NILO), który otrzymał rejestrację, odpowiednio, w latach 2007 i 2010. Leki te są silniejsze niż IM i skuteczne u znacznej części chorych nieodpowiadających na wcześniejsze leczenie [6-8]. Wytyczne co do sposobu postępowania i dążenia do określonych celów w postaci stopnia i rodzaju uzyskanych remisji w odpowiednich punktach czasowych zawarto w zaleceniach Europejskiej Sieci Białaczkowej (ELN, European LeukemiaNet) [9-11], a w Polsce — w rekomendacjach Polish Adult Leukemia Group (PALG) [12]. Wytyczne te zmieniały się wraz z rozwojem wiedzy na temat skuteczności leczenia TKI.

W pracy przedstawiono przypadek chorej, która po nieoptymalnym leczeniu IM została zakwalifikowana w drugiej linii do terapii NILO. Uzyskała bardzo dobry efekt leczenia w postaci całkowitej remisji hematologicznej (CHR, complete hematologic response), cytogenetycznej (CCR, complete cytogenetic response) i głębokiej molekularnej (DMR, deep molecular response). Wystąpiło powikłanie $\mathrm{w}$ postaci wystąpienia zaburzeń metabolicznych u pacjentki stwierdzono cukrzycę, ale dzięki zastosowanemu leczeniu wspomaganemu dietą możliwa była dalsza skuteczna terapia CML.

\section{Opis przypadku}

W lutym 2012 roku do kliniki zgłosiła się pacjentka $z$ podejrzeniem CML. W połowie miesiąca wykonała badania okresowe wymagane przez zakład pracy, w których stwierdzono hiperleukocytozę i skierowano ją do szpitala. Do tego czasu nie chorowała przewlekle i nie przyjmowała leków na stałe. Jedyną zgłaszaną dolegliwością były niewielkie, okresowe bóle w lewym podżebrzu występujące od kilku tygodni. Przy przyjęciu w badaniu przedmiotowym - poza otyłością ze wskaźnikiem masy ciała (BMI, body mass index) wynoszącym 38 i podwyższonymi wartościami ciśnienia tętniczego - nie stwierdzono innych nieprawidłowości (wątroba i śledziona były niewyczuwalne). W morfologii krwi liczba leukocytów (WBC, white blood count) wynosiła $231 \mathrm{G} / 1$, stężenie hemoglobiny $(\mathrm{Hb}) 10,9 \mathrm{~g} / \mathrm{dl}$, a liczba płytek (PLT, plateles) $410 \mathrm{G} / \mathrm{l}$. W rozmazie wykazano: 3\% blastów, 6\% promielocytów, $7 \%$ mielocytów, $11 \%$ metamielocytów, $21 \%$ granulocytów pałeczkowatych, $33 \%$ granulocytów podzielonych, $7 \%$ granulocytów kwasochłonnych, 7\% granulocytów zasadochłonnych, $5 \%$ limfocytów. Wykonano biopsję szpiku. W ocenie cytologicznej opisano pobudzenie układu granulocytarnego mogące odpowiadać CML, a w badaniu cytogenetycznym - obecność translokacji $\mathrm{t}(9 ; 22)(\mathrm{q} 34 ; \mathrm{q} 11,2)$ we wszystkich 22 metafazach. 
W badaniu molekularnym reakcji łańcuchowej polimerazy $z$ odwrotną transkrypcją (RT-PCR, reverse-transcriptase polymerase chain reaction) stwierdzono obecność transkryptu $B C R-A B L 1$ p210. Na tej podstawie potwierdzono rozpoznanie CML w fazie przewlekłej. W ocenie wykazano niskie wartości wskaźników prognostycznych Sokala, Hasforda i EUTO. Oczekując na wyniki pobranych badań, rozpoczęto leczenie hydroksymocznikiem $\mathrm{w}$ dawce dobowej od 1,5-2,0 g. Jednocześnie ze względu na utrzymujące się podwyższone wartości ciśnienia tętniczego (maksymalnie do 170/ /95 mm Hg) rozpoznano także nadciśnienie tętnicze i włączono leczenie inhibitorem konwertazy angiotensyny (enalapril - preparat Enarenal ${ }^{\circledR} 2 \times 10 \mathrm{mg}$ ) $z$ dobrym efektem. Wstępne cytoredukcyjne leczenie hydroksymocznikiem stosowane przez 8 tygodni pozwoliło uzyskać redukcję WBC bez osiągnięcia CHR.

W kwietniu 2012 roku rozpoczęto leczenie imatynibem w dawce $400 \mathrm{mg} /$ dobę. Terapia była dobrze tolerowana i po miesiącu uzyskano CHR. Ocenę cytogenetyczną przeprowadzono w 3., 6. i 12. miesiącu, osiągając redukcję odsetka metafaz $\mathrm{z}$ obecnością chromosomu $\mathrm{Ph}$, odpowiednio, do $9 \%, 3,3 \%$ i $2,8 \%$. Podczas trwania terapii w latach 2012 i 2013 obowiązywały zalecenia ELN jeszcze z 2009 roku [10], kiedy takie wyniki uważano za suboptymalne. W takiej sytuacji nie istniały sztywne wytyczne, mimo to istniała możliwość wyboru w postaci: zmiany leczenia na TKI II generacji, utrzymania leczenia IM w tej samej dawce lub zwiększenia do dawki do $600 \mathrm{mg} /$ dobę. W przypadku chorej wybrano trzecią możliwość. Jednak w kolejnej ocenie cytogenetycznej po 18 miesiącach terapii nie stwierdzono poprawy — odsetek metafaz $\mathrm{Ph}(+)$ wynosił $3 \%$.

$\mathrm{Na}$ tej podstawie rozpoznano oporność pierwotną i od grudnia 2013 roku rozpoczęto leczenie NILO w dawce $800 \mathrm{mg}$ /dobę. Po 3 miesiącach pacjentka osiagnęła CCR, a w badaniu molekularnym metodą ilościowej polimerazowej reakcji łańcuchowej z czasie rzeczywistym (RQ-PCR, real-time quantitative polymerase chain reaction) wykazano większą remisję molekularną (MMR, major molecular response) na poziomie MR4,0. W kolejnych punktach czasowych po 6 i 9 miesiącach remisja pogłębiła się do MR4,5, po 12 miesiącach zaś - do MR5 z nieoznaczalnym transkryptem $B C R-A B L 1$. Głęboka remisja molekularna utrzymywała się przez całe leczenie. Skuteczność terapii NILO okazała się doskonała, pojawiły się jednak objawy nietolerancji. W 2. miesiącu leczenia wystąpiły świąd skóry i drobnogrudkowa wysypka alergiczna
1. stopnia według Światowej Organizacji Zdrowia (WHO, World Health Organization). Pacjentka otrzymała lek antyhistaminowy (cetyryzyna preparat $Z$ yrtec ${ }^{\circledR} 15 \mathrm{mg} /$ d.) i zmiany ustapiły po miesiącu jego stosowania. W 3 miesiącu leczenia pojawiły się dolegliwości ze strony przewodu pokarmowego w postaci biegunki (1. stopnia wg WHO). Tym razem wystarczającym postępowaniem była zmiana diety. Od początku leczenia TKI wykonywano badania laboratoryjne oceniające stan wydolności wątroby i nerek, a od momentu włączenia NILO — także stężenie glukozy, enzymy trzustkowe i lipidogram. Parametry oceniające czynność nerek, wątroby i trzustki mieścily się w granicach normy. Parametry lipidowe były nieco podwyższone (stężenie cholesterolu $200-220 \mathrm{mg} / \mathrm{dl}$, stężenie triglicerydów $120-180 \mathrm{mg} / \mathrm{dl}$ ), ale nie wymagały zastosowania farmakoterapii — zalecono stosowanie diety. Problemem natomiast stała się nietolerancja glukozy. Podczas leczenia IM stężenie glukozy było na górnej granicy normy (98-100 mg/dl), a w ciągu kilku miesięcy po włączeniu NILO osiągnęło wartość $120 \mathrm{mg} / \mathrm{dl}$. Po roku leczenia rozpoznano nieprawidłową glikemię na czczo i zalecono dietę hipoglikemiczną oraz zmniejszenie masy ciała. Ponieważ postępowanie to było nieskuteczne, pacjentkę skierowano do diabetologa. Wykonano u niej doustny test tolerancji glukozy. Wartość glikemii w 120 . minucie po obciążeniu glukozą wynosiła $124 \mathrm{mg} / \mathrm{dl}$. Diabetolog podtrzymał rozpoznanie nieprawidłowej glikemii na czczo i utrzymał dotychczasowe zalecenia. Kolejne kontrolne badania stężenia glukozy wykonywano w odstępach miesięcznych. Ponieważ wartości te narastały (do $130-159 \mathrm{mg} / \mathrm{dl}$ ), w maju 2015 roku diabetolog rozpoznał cukrzycę i włączył leczenie. Początkowo był to gliklazid (Diaprel MR ${ }^{\circledR} 60 \mathrm{mg} / \mathrm{d}$.), do którego po 2 miesiącach dołączono metforminę (Glucophage ${ }^{\circledR}$ ) w stopniowo zwiększanej dawce (docelowo $1000 \mathrm{mg}$ / /d.). Zastosowane leczenie hipoglikemizujące zapewniło obniżenie glikemii na czczo do wartości poniżej $120 \mathrm{mg} / \mathrm{dl}$, a po posiłku - 130-140 mg/dl. Stężenie hemoglobiny glikowanej $\left(\mathrm{HbA}_{1 \mathrm{c}}\right)$ pozostawało $\mathrm{w}$ granicach normy lub nieznacznie powyżej $7 \%$. Parametry lipidowe znajdowały się w normie (stężenie cholesterolu $174 \mathrm{mg} / \mathrm{dl}$, stężenie triglicerydów $150 \mathrm{mg} / \mathrm{dl}$ ).

Ostatecznie pacjentka $\mathrm{z}$ opornością pierwotną na IM jest skutecznie leczona NILO - uzyskała CCR i DMR. Nietolerancja terapii w postaci zaburzeń metabolizmu glukozy została skutecznie opanowana doustnymi lekami hipoglikemicznymi, dzięki czemu leczenie może być bezpiecznie kontynuowane. 


\section{Dyskusja}

Od momentu pojawienia się na początku XXI wieku TKI w leczeniu CML doszło do rewolucyjnych zmian. Leki te stały się standardem, a stopniowo nabywana wiedza na temat ich skuteczności pozwoliła wypracować optymalne wytyczne postępowania, które ELN opublikowała w latach 2006, 2009 i 2013, a modyfikacje wynikały $z$ postępu wiedzy i większych możliwości terapeutycznych [9-11]. Według zaleceń z 2009 roku w przypadku uzyskania odpowiedzi suboptymalnej podczas leczenia IM istniała możliwość kontynuowania tej terapii w dotychczasowej dawce, zwiększenia jej do $600 \mathrm{mg}$ /dobę lub zamiany na TKI II generacji. W 2013 roku termin „odpowiedź suboptymalna” zastąpiono „ostrzeżeniem” i w przypadku braku odpowiedzi optymalnej zalecano zmianę leczenia na TKI II generacji. Opisaną pacjentkę leczono jeszcze według zaleceń z 2009 roku.

Mimo bardzo dobrych efektów leczenia IM okazało się, że nie wszyscy chorzy odnoszą korzyść $z$ tej terapii. Analiza danych badania IRIS (International randomized study of interferon versus STI571) po $5,6,7,8$, a następnie po 10 latach wykazała, że ostatecznie $48 \%$ pacjentów przerwało leczenie. Wśród powodów wymieniano nieskuteczność, nietolerancję, a także inne przyczyny [13-17]. Ratunkiem dla tych pacjentów było zastosowanie NILO lub DAZA. Leczenie TKI II generacji jest skuteczne u znacznej części chorych, co udowodniono w badaniach klinicznych $[18,19]$. Dzięki nim można zapewnić pacjentom kontynuację efektywnej terapii. Przykładem może być opisywany przypadek. Mimo oporności w pierwszej linii na leczenie IM $\mathrm{w}$ drugiej linii osiągnięto nie tylko CCR, ale także MMR, a nawet DMR.

Sukces terapeutyczny u części pacjentów może być jednak obarczony wystąpieniem działań niepożądanych. W przypadku NILO występują najczęściej ( $\mathrm{c}>10 \%$ leczonych): nudności, bóle brzucha, wysypka, świąd skóry, bóle głowy, bóle mięśniowe, uczucie zmęczenia. Nasilenie tych dolegliwości nie jest zwykle na tyle duże, żeby wymagało odstawienia leku. Toksyczność hematologiczna w postaci: małopłytkowości (18\%), leukopenii (15\%) i niedokrwistości (8\%) może być skutecznie opanowana redukcją dawki. Ponadto NILO może być przyczyną hepatotoksyczności, wzrostu stężenia enzymów trzustkowych, zaburzeń lipidowych oraz hiperglikemii. Niebezpieczne moga być incydenty sercowo-naczyniowe, wydłużenie odstępu QT (sprzyjające zaburzeniom rytmu) oraz rozwój choroby okluzyjnej tętnic obwodowych
(PADO, peripheral arteria occlusive disease) [20-22]. Te ostatnie sytuacje wymagają nie tylko wzmożonej czujności i włączenia odpowiedniej terapii, ale także nawet zaprzestania leczenia NILO.

W przypadku omawianej chorej zmiany skórne i zaburzenia ze strony przewodu pokarmowego miały krótkotrwały i przejściowy charakter. Ustąpiły po zastosowanym leczeniu, tak jak w większości przypadków [23]. Istotnym problemem stała się natomiast hiperglikemia. Nie było to zaskakujące, ponieważ wpływ NILO na metabolizm glukozy dostrzeżono już $\mathrm{w}$ pierwszych latach stosowania tego leku w terapii CML i $z$ tego względu stał się przedmiotem obserwacji i badań [24]. W badaniu ENESTnd (Evaluating Nilotinib Efficacy and Safety in Clinical Trials-Newly Diagnosed Patients) opisano rozwój cukrzycy u $19 \%$ chorych leczonych NILO w porównaniu $z 2 \% \mathrm{w}$ grupie otrzymującej IM po 5 latach obserwacji [25]. W badaniach ENIGMA1 i ENIGMA2 wykazano wystąpienie hiperglikemii, hiperinsulinemii i insulinooporności oraz hipercholesterolemii po 3 miesiącach leczenia NILO $[26,27]$.

Wiadomo, że rozpoznanie zaburzeń tolerancji glukozy na początku ich rozwoju i zastosowanie odpowiedniego postępowania w postaci modyfikacji stylu życia pozwalają spowolnić ten proces, a w przypadku rozwoju cukrzycy — włączyć skuteczne leczenie i zapobiec rozwojowi powikłań. Szczególną uwagę należy zwrócić na osoby $z$ czynnikami ryzyka zachorowania na cukrzycę, takimi jak wiek powyżej 45. roku życia, otyłość (szczególnie brzuszna), mała aktywność fizyczna, hiperglikemia we wcześniejszych badaniach, zaburzenia gospodarki lipidowej, nadciśnienie tętnicze, choroby układu krążenia, stosowanie leków o działaniu diabetogennym, występowanie cukrzycy w rodzinie, a w przypadku kobiet należy pamiętać o wywiadzie $z$ okresu ciąży (cukrzyca u kobiet w ciąży, urodzenie dziecka o masie ciała $>4 \mathrm{~kg}$ ). Ponieważ pacjentka spełniała część $z$ wymienionych czynników ryzyka, pozostawała pod uważną obserwacją od początku leczenia NILO i w odpowiednim momencie włączono leczenie. Kryteria wyrównania metabolicznego cukrzycy to obniżenie stężenia glukozy na czczo i po posiłkach, ale przede wszystkim dążenie do normalizacji wartości $\mathrm{HbA}_{1 \mathrm{c}}$. Zaleca się utrzymanie wartości $\mathrm{HbA}_{1 \mathrm{c}}$ poniżej $7 \%(53 \mathrm{mmol} / \mathrm{mol})$, co chroni przed rozwojem powikłań. Ważna jest także kontrola profilu lipidowego pacjentów, ponieważ są oni narażeni na wystąpienie zespołu metabolicznego, który sprzyja powikłaniom układu sercowo-naczyniowego. Istnieją również precyzyjnie określone zalecenia związane $z$ wiekiem cho- 
rego, wspólistniejącymi chorobami i istniejącymi już powikłaniami [28].

Dobrze kontrolowana cukrzyca nie jest przeciwwskazaniem do terapii NILO zarówno wtedy, gdy stosowanie tego leku jest włączane, jak tė் wówczas, gdy dochodzi do rozwoju zaburzeń glikemicznych w trakcie leczenia białaczki. Należy jednak pamiętać o interakcjach zachodzących między doustnymi lekami przeciwcukrzycowymi a TKI. Inhibitory kinaz tyrozynowych są inhibitorami podjednostki CYP3A4 cytochromu P450 i zwiększają ekspozycję na leki hipoglikemiczne, nie tylko nasilając ich działanie, ale także powodując działania niepożądane. Niektóre $z$ leków przeciwcukrzycowych mogą z kolei zwiększać ekspozycję na TKI [29]. Chorzy leczeni jednocześnie jednymi i drugimi lekami wymagają więc szczególnej uwagi.

\section{Podsumowanie}

Podsumowując, można stwierdzić, że u opisywanej pacjentki początkowe nieskuteczne leczenie IM $z$ sukcesem zastąpiono terapią NILO, uzyskując nie tylko CCR, ale także DMR, dzięki czemu można zakwalifikować chorą do grupy o najlepszym rokowaniu. Powikłanie w postaci cukrzycy jest skutecznie kontrolowane doustnymi lekami przeciwcukrzycowymi i nie stanowi przeciwwskazania do kontynuacji leczenia CML.

\section{Piśmiennictwo}

1. Hoffmann VS, Baccarani M, Hasford J, et al. The EUTOS population-based registry: incidence and clinical characteristics of 2904 CML patients in 20 European countries. Leukemia. 2015; 29(6): 1336-1343, doi: 10.1038/leu.2015.73, indexed in Pubmed: 25783795 .

2. Nowell PC, Hungerford DA. Chromosome studies on normal and leukemic human leukocytes. J Natl Cancer Inst. 1960; 25: 85-109, indexed in Pubmed: 14427847.

3. Rowley JD. Letter: A new consistent chromosomal abnormality in chronic myelogenous leukaemia identified by quinacrine fluorescence and Giemsa staining. Nature. 1973; 243(5405): 290-293, indexed in Pubmed: 4126434.

4. Quintás-Cardama A, Cortes J. Molecular biology of bcr-abl1-positive chronic myeloid leukemia. Blood. 2009; 113(8): 1619-1630, doi: 10.1182/blood-2008-03-144790, indexed in Pubmed: 18827185 .

5. O'Brien SG, Guilhot F, Larson RA, et al. IRIS Investigators. Imatinib compared with interferon and low-dose cytarabine for newly diagnosed chronic-phase chronic myeloid leukemia. N Engl J Med. 2003; 348(11): 994-1004, doi: 10.1056/NEJMoa022457, indexed in Pubmed: 12637609.

6. Gracia-Gutierrez V, Herrera P, Abalo L, et al. Impact of second-generation tyrosine kinase inhibitors as second line treatment for patients with chronic myeloid leukemia. Blood. 2011; 118: abstract 3780 .
7. Cortes J, Kim DW, Raffoux E, et al. Efficacy and safety of dasatinib in imatinib-resistant or -intolerant patients with chronic myeloid leukemia in blast phase. Leukemia. 2008; 22(12): 2176-2183, doi: 10.1038/leu.2008.221., indexed in Pubmed: 18754032.

8. Giles FJ, Abruzzese E, Rosti G, et al. Nilotinib is active in chronic and accelerated phase chronic myeloid leukemia following failure of imatinib and dasatinib therapy. Leukemia. 2010; 24(7): 1299-1301, doi: 10.1038/leu.2010.110, indexed in Pubmed: 20520639.

9. Baccarani M, Saglio G, Goldman J, et al. European LeukemiaNet. Evolving concepts in the management of chronic myeloid leukemia: recommendations from an expert panel on behalf of the European LeukemiaNet. Blood. 2006; 108(6): 1809-1820, doi: 10.1182/ /blood-2006-02-005686, indexed in Pubmed: 16709930.

10. Baccarani M, Cortes J, Pane F, et al. European LeukemiaNet. Chronic myeloid leukemia: an update of concepts and management recommendations of European LeukemiaNet. J Clin Oncol. 2009; 27(35): 6041-6051, doi: 10.1200/JCO.2009.25.0779, indexed in Pubmed: 19884523.

11. Baccarani M, Deininger MW, Rosti G, et al. European LeukemiaNet recommendations for the management of chronic myeloid leukemia: 2013. Blood. 2013; 122(6): 872-884, doi: 10.1182/ /blood-2013-05-501569, indexed in Pubmed: 23803709.

12. Sacha T, Lewandowski K, Hellmann A, et al. Rekomendacje PALG dotyczące diagnostyki i leczenia przewlekłej białaczki szpikowej w 2013 r. Acta Haematol Pol. 2013; 44(4): 345-362, doi: 10.1016/j. achaem.2013.07.008.

13. Druker BJ, Guilhot F, O'Brien SG, et al. IRIS Investigators. Five-year follow-up of patients receiving imatinib for chronic myeloid leukemia. N Engl J Med. 2006; 355(23): 2408-2417, doi: 10.1056/ /NEJMoa062867, indexed in Pubmed: 17151364.

14. Hochhaus A, O'Brien SG, Guilhot F, et al. IRIS Investigators. Six-year follow-up of patients receiving imatinib for the first-line treatment of chronic myeloid leukemia. Leukemia. 2009; 23(6): 1054-1061, doi: 10.1038/leu.2009.38, indexed in Pubmed: 19282833.

15. O'Brien SG, Guilhot F, Goldman JM, et al. International randomized study of interferon versus STI571 (IRIS) 7-year follow-up: sustained survival, low rate of transformation and increased rate of major molecular response (MMR) in patients with newly diagnosed chronic myeloid leukemia in chronic phase (CMLCP) treated with imatynib (IM). Blood. 2008; 112(11): 76, abstract 186.

16. Deiniger M, O'Brien SG, Guilhot F, et al. nternational randomized study of interferon and STI571 (IRIS) 8-year follow-up: sustained survival and low risk for progression in patients with newly diagnosed chronic myeloid leukemia in chronic phase treated with imatynib. Blood. 2009; 114: abstract 1126.

17. Hochhaus A, Larson RA, Guilhot F, et al. Long-term outcomes of imatinib treatment for chronic myeloid leukemia. N Engl J Med. 2017; 376(10): 917-927, doi: 10.1056/NEJMoa1609324., indexed in Pubmed: 28273028.

18. Giles FJ, Coutre PDle, Pinilla-Ibarz J, et al. Nilotinib in imatinib-resistant or imatinib-intolerant patients with chronic myeloid leukemia in chronic phase: 48 -month follow-up results of a phase II study. Leukemia. 2012; 27(1): 107-112, doi: 10.1038/leu.2012.181.

19. Shah NP, Guilhot F, Cortes JE, et al. Long-term outcome with dasatinib after imatinib failure in chronic-phase chronic myeloid leukemia: follow-up of a phase 3 study. Blood. 2014; 123(15): 2317-2324, doi: 10.1182/blood-2013-10-532341, indexed in Pubmed: 24569263.

20. Tasigna (nilotinib) [prescribing information]. Novartis Pharmaceuticals Corporation 2015. 
21. Kim TD, Rea D, Schwarz M, et al. Peripheral artery occlusive disease in chronic phase chronic myeloid leukemia patients treated with nilotinib or imatinib. Leukemia. 2013; 27(6): 1316-1321, doi: 10.1038/leu.2013.70, indexed in Pubmed: 23459449.

22. Aichberger KJ, Herndlhofer S, Schernthaner GH, et al. Progressive peripheral arterial occlusive disease and other vascular events during nilotinib therapy in CML. Am J Hematol. 2011; 86(7): 533-539, doi: 10.1002/ajh.22037, indexed in Pubmed: 21538470.

23. Jabbour E, Deininger M, Hochhaus A. Management of adverse events associated with tyrosine kinase inhibitors in the treatment of chronic myeloid leukemia. Leukemia. 2011; 25(2): 201-210, doi: 10.1038/leu.2010.215, indexed in Pubmed: 20861918.

24. Valent P. Severe adverse events associated with the use of second-line BCR/ABL tyrosine kinase inhibitors; preferential occurrens in patients with comorbiditis. Haematologica. 2011; 96(10): 1395-1397, doi: 10.3324/haematol.2011.052076., indexed in Pubmed: 21972208

25. Larson RA, Kim DW, Jootar S, et al. ENESTnd 5-year (y) update: Long-term outcomes of patients (pts) with chronic myeloid leu- kemia in chronic phase (CML-CP) treated with frontline nilotinib (NIL) versus imatinib (IM). J Clin Oncol. 2014; 32(15 Suppl): 7073, doi: 10.1200/jco.2014.32.15_suppl.7073.

26. Racil Z, Razga F, Drapalova J, et al. Mechanism of impaired glucose metabolism during nilotinib therapy in patients with chronic myelogenous leukemia. Haematologica. 2013; 98(10): e124-e126, doi: 10.3324/haematol.2013.086355, indexed in Pubmed: 23716549.

27. Racil Z, Belohlavkova P, Cetkovsky P. Comparison of glucose and lipid metabolism abnormality during nilotinib, imatinib and dasatinib therapy — results of Enigma 2 study. Blood. 2014; 124: 1813.

28. Zalecenia kliniczne dotyczące postępowania $u$ chorych na cukrzycę 2017. Stanowisko Polskiego Towarzystwa Diabetologicznego. Diabetol Klin. 2017; 3(Suppl A): A1-A82.

29. Sacha T, Szmit S, Zozulińska-Ziółkiewicz D, et al. Zalecenia dotyczące oceny schorzeń współistniejących u chorych na przewlekłą białaczkę szpikową w procesie wyboru inhibitora kinaz tyrozynowych. Acta Haematol Pol. 2016; 47(3): 184-196, doi: 10.1016/j.achaem.2016.06.001.

\section{Komentarz}

Wybór optymalnego leku drugiej linii powinien być dokonywany $z$ uwzględnieniem jego profilu działań niepożądanych oraz chorób wspólistniejących u konkretnego chorego. Nilotynib wywołuje u części chorych hiperglikemię i może, między innymi w mechanizmie poreceptorowej oporności na insulinę, prowadzić do pojawienia się lub nasilenia zaburzeń metabolicznych typowych dla cukrzycy.
Przedstawiony przypadek ilustruje taką właśnie sytuację, a skuteczne zapanowanie nad tymi zaburzeniami poprzez wdrożenie odpowiedniego postępowania u chorej, która osiągnęła głęboką odpowiedź molekularną, potwierdza słuszność zalecenia, zgodnie $z$ którym istnienie lub pojawienie się cukrzycy nie stanowi przeciwwskazania do wdrożenia lub kontynuacji leczenia nilotynibem.

dr hab. n. med. Tomasz Sacha Katedra Hematologii, Collegium Medicum, Uniwersytet Jagielloński, Kraków 